\title{
Curved curtain wall for the extension of aspire academy qatar
}

\begin{abstract}
The here presented paper deals with a case study of façade structural design for the extension of Aspire Academy in Doha Qatar. Different curtain walls using stick system for various spans and heights were designed. All the external curtain walls are subjected to a wind load of $2.3 \mathrm{KPa}$ as per the project specification. Double glazed units are considered for the curtain walls. The building has a curved elevation on the East and West side where stick curtain wall system is considered and the analysis and design is presented in this paper. The mullions of the curtain walls are curved member along the strong axis having high inertia which conventionally was not possible to achieve such section with a normal extruded profile; hence Aluminium sheets were cut in curved shapes to form the desired shape. The transoms are conventional extruded profile of the same depth as those of the mullions. The paper addresses some technical issues together with the design of the curtain wall that are believed to be useful for the façade structural design.
\end{abstract}

Keywords: curtain walls, built up sections, mullions, transoms, glazed units, aluminium profiles
Volume 2 Issue 6 - 2017

\author{
Muhammad Tayyab Naqash, Ayed Eid \\ Alluqmani \\ Department of Civil Engineering, Islamic University in Madinah \\ Al Munaworah, Saudi Arabia
}

Correspondence: Muhammad Tayyab Naqash, Department of Civil Engineering, Islamic University in Madinah Al Munaworah, Saudi Arabia, Email engr.tayyabnaqash@gmail.com

Received: April 27, 2017 | Published: May 25, 2017

\section{Introduction}

Transparent building façades are really the ongoing trend these days. Complex structural geometry, extreme temperatures, large openings and bad weather conditions make it quite challenging for the façade structural engineers to envelop the building fulfilling the efficient energy consumptions and optimum resistant to the external forces. Middles east countries has huge sunshine throughout the year and having high temperatures, still the use of glass as glazing units in the façade is the general trend specially for skyscrapers. Use of Aluminum with glass as glazing unit is very common and therefore in extreme weather, expansion of Aluminium is another challenging task to be cover by the façade engineers. Weather condition in Doha is extreme; it has high winds and high temperature in summer that makes it difficult to fulfill the design requirements together with the Architectural constraints of the building façade which goes side by side. ${ }^{1}$ In this paper a double curvature curtain wall (highlighted in black in Figure 1) has been designed and examined. The considered curtain wall for the building has Maximum Mullion spacing (Maximum Transom Length) of around $3 \mathrm{~m}$; therefore it is the worst scenario for the design calculations. All the transoms are assumed pinned connected, transferring only shear forces. Stresses and deflection checks obtained from the numerical model ${ }^{2}$ have been carried out for glass and Aluminum mullions. The brackets are realized and checked for the corresponding induced forces and they are modeled separately in Robot software. ${ }^{3}$ Instead the anchor bolts are designed using Hilti profis software. ${ }^{4}$ All the structural system has been found SAFE according to different acceptance criterion. ${ }^{5-7}$

Regarding Glass, Aluminum and other elements, the deal load is calculated by the software (SAP 2000). ${ }^{2}$ The wind load is specified as $2.3 \mathrm{kPa}$ as per the project specification. With regards to the temperature Loading, the Initial temperature is assumed to be $\pm 10^{\circ} \mathrm{C}$, whereas the final temperature to be $\pm 50^{\circ} \mathrm{C}$, as the coefficient of thermal expansion for Aluminium $(\alpha)$ equals $23 \times 10^{-6}$, therefore the change in length, i.e., $\Delta_{\mathrm{L}}$ equals $\alpha . \Delta_{\mathrm{L}}$. $\mathrm{L}=\left(23 \times 10^{-6}\right) .(40) .(6500)$ equals
$5.98 \mathrm{~mm}$. The expansion of Aluminium material is more critical than that of steel material, therefore in this case vertical slots are provided to accommodate thermal expansion and contraction, and hence temperature load is not accounted in the analysis model. In some cases where slots may not be favorable and not provided, stresses due to temperature need to be verified prior to the installation. ${ }^{8-10}$

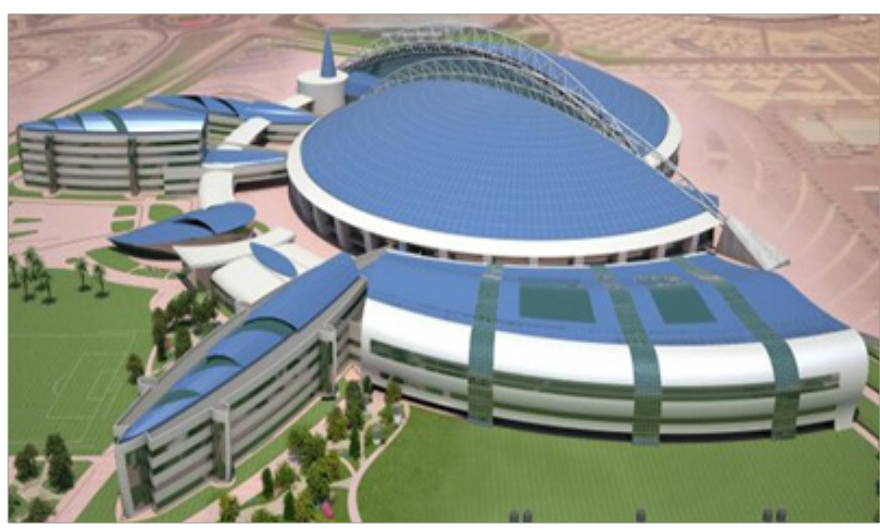

Figure I Extension of aspire academy (Double curvature curtain wall highlighted in black).

\section{Numerical modeling}

\section{General and profiles}

A built up section is fabricated by cutting Aluminium sheets with Mullion nose fixed to it. The width of Mullion is $52 \mathrm{~mm}$ whereas the depth equals $223 \mathrm{~mm}$. In ALUTEC facility it was not possible to create a Mullion being bend in the strong axis from an Aluminum tube that simultaneously satisfy the deflection and strength requirements. Moreover smaller tube with steel insert is also not a practical solution and in this case the curtain wall has double curves (concave and convex) creating a radius of curvature of about $11 \mathrm{~m}$ as shown in Figure 2. Therefore $4 \mathrm{~mm}$ thick sheets are cut in precise 
shape to achieve the desire curve and then screwed to the sides of $10 \mathrm{~mm}$ thick Aluminium sheets as shown in Figure 2. These screws are spaced at around $200 \mathrm{~mm}$ center to center, thus gives rise to very strong Aluminum tube. The local strength check of this built up tube is considered beyond the scope of the current paper and can be address in a separate article. Mullion nose, obtained from Technal FM 257 system, is mechanically fixed through screws at the front of the built up Mullion. Transoms, that are pinned connected to the Mullions at the two sides, are supporting the gravity (dead) load of glass and composite panels as per Technal FM 257 system, see Catalogue page of Technal in Figure 3. ${ }^{11,12}$

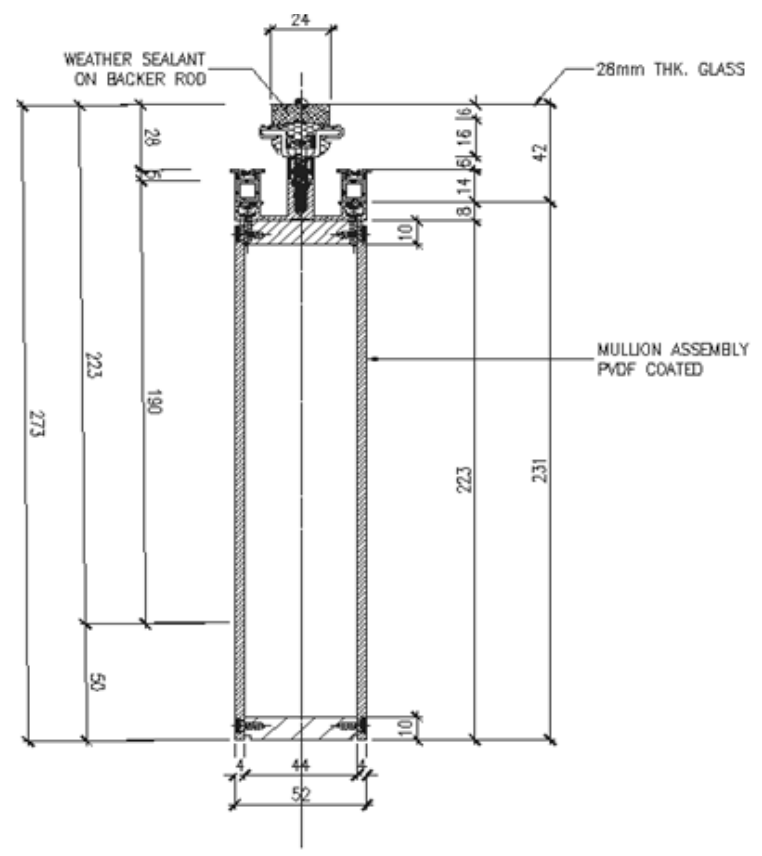

Figure 2 Built up mullion profile.

Grid transom profiles

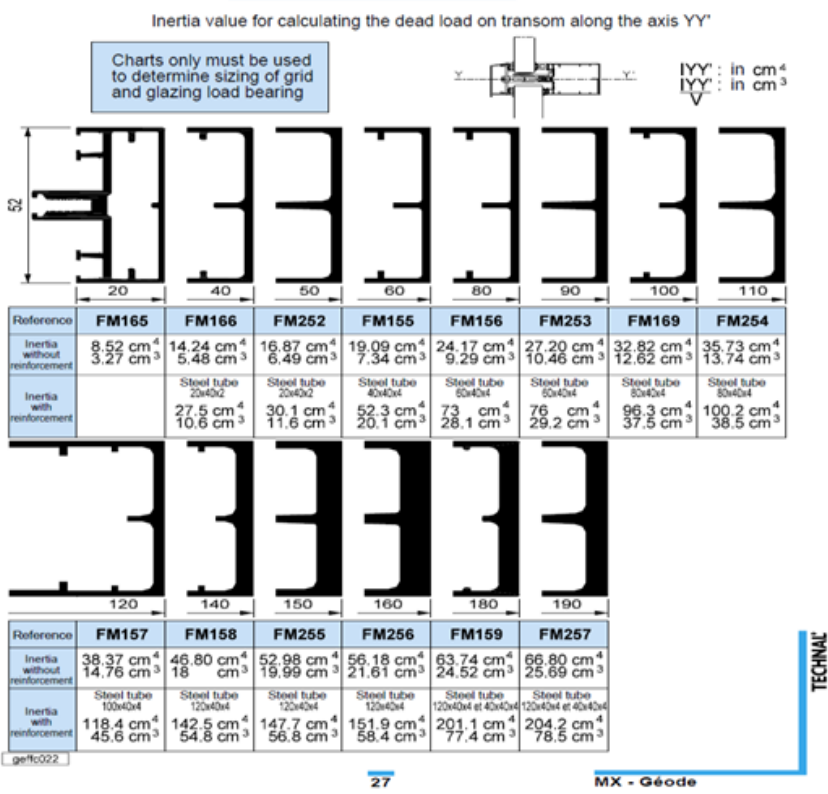

Figure 3 Transoms profile inertia with and without steel insert (Technal system).

\section{Geometry}

The complete geometry of the typical curtain wall is shown in Figure $4 \& 5$, which represents the east elevation continuing from ground floor to top floor. The curtain wall is connected at four locations, top (roof level) is supported by the space frame, bottom (ground level) is supported by reinforce concrete beam, whereas two reinforced concrete floor slabs provide supports at the intermediate levels. In order to allow the Mullions to breath in vertical direction (thermal expansion and contraction), slots are provided; therefore temperature load does not induce any stresses in the Mullions.

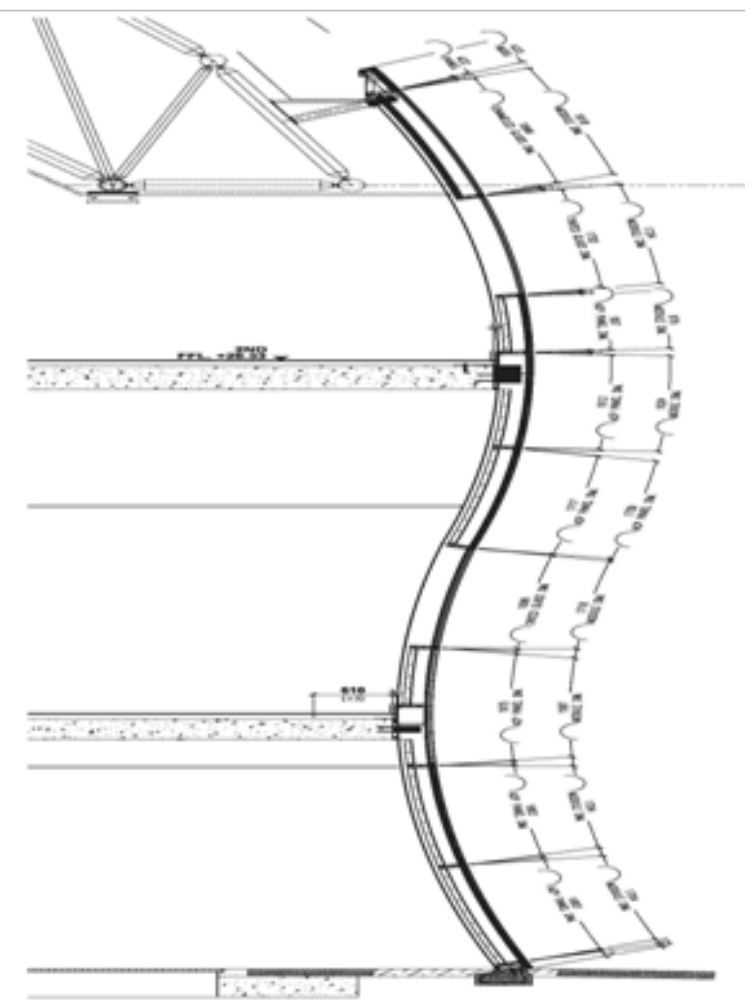

Figure 4 Curtain wall section view.

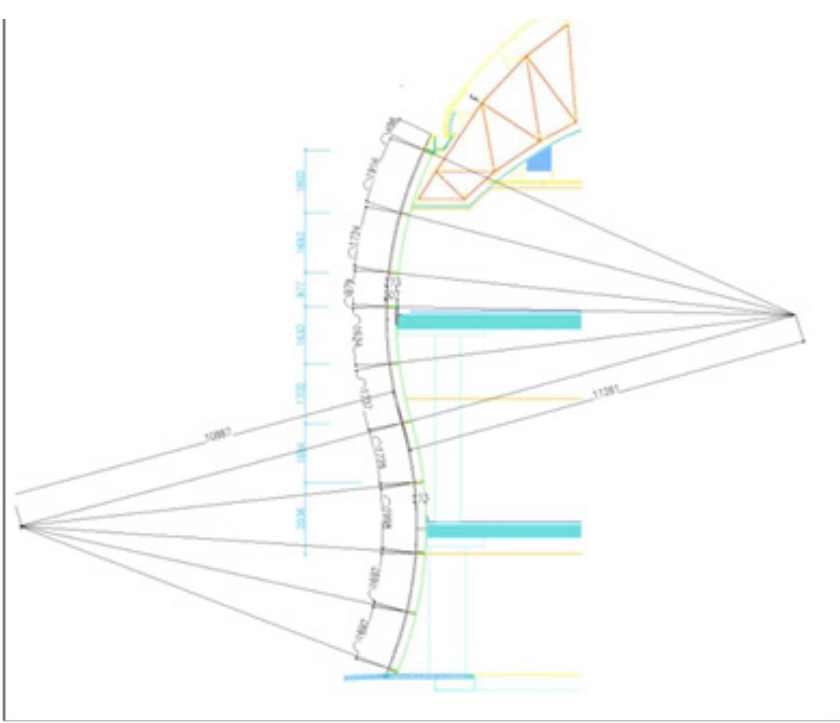

Figure $\mathbf{5}$ Curtain wall section view showing radius of curvature. 


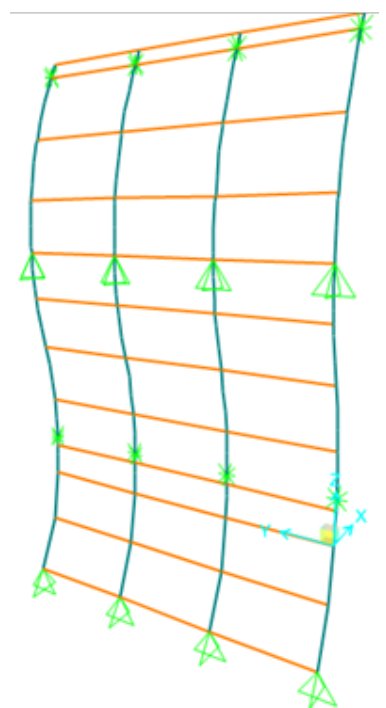

(a)

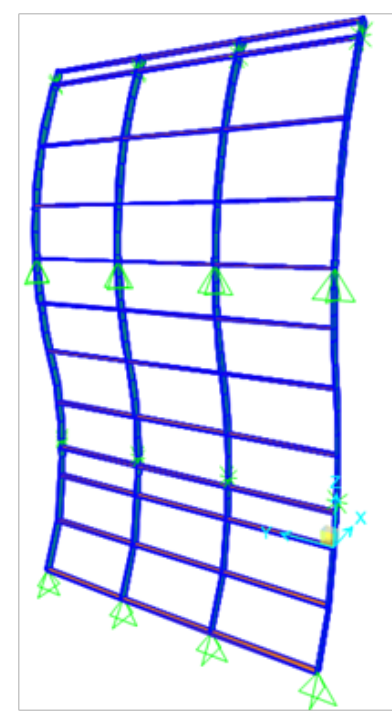

(b)
Figure 6 Curtain wall, (a) Model and (b) Numerical model 3D.

\section{Numerical model}

SAP 2000 numerical software is used to model the curtain wall. The transoms are pin connected (transferring only shear) as shown in Figure 6. Hinge supports are used, two restraining the translations in $\mathrm{x}, \mathrm{y}$ as well as $\mathrm{z}$, whereas the rest two are restraining only translation in $\mathrm{x}$ and $\mathrm{y}$ and therefore allows the slight movement of the curtain wall in $\mathrm{z}$ (vertical) direction in case if any (Figure 7). The coordinates of the Joints are shown in Table 1.
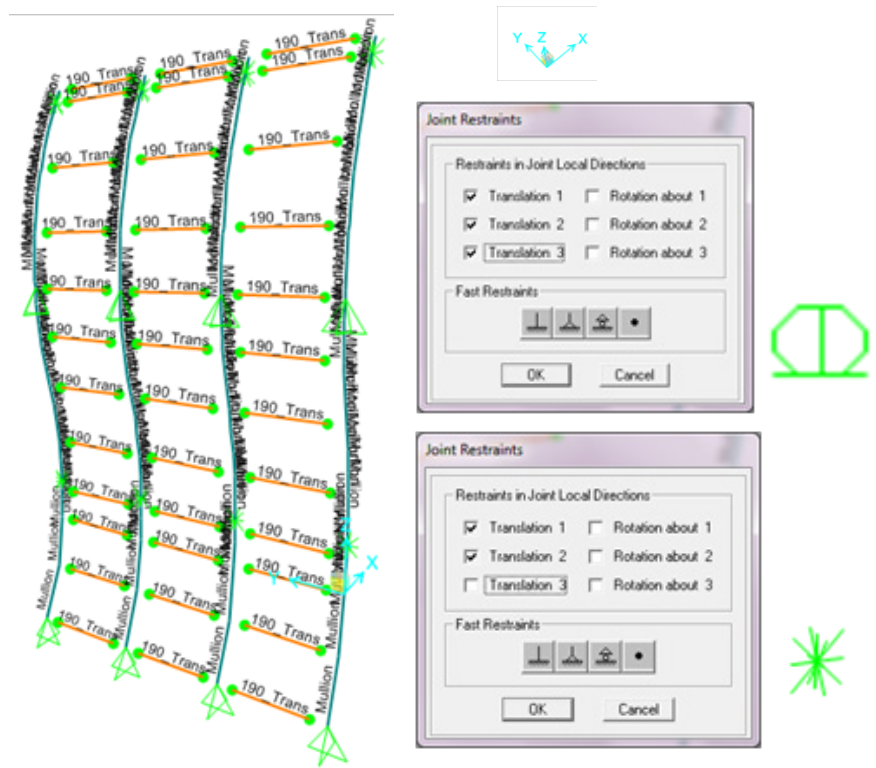

Figure 7 Curtain wall, (a) Frame releases and restraints and (b) Restraints condition.

Table I Joint coordinates

\begin{tabular}{|c|c|c|c|c|c|c|c|c|c|}
\hline Joint & Coord sys & Coord type & XorR & $\mathbf{Y}$ & $\mathbf{Z}$ & Special Jt & Global X & GlobalY & Global Z \\
\hline Text & Text & Text & $\mathrm{m}$ & $\mathrm{m}$ & $\mathrm{m}$ & Yes/No & $\mathrm{m}$ & $\mathrm{m}$ & $\mathrm{m}$ \\
\hline I & Global & Cartesian & 3 & II & 0 & Yes & 3 & 11 & 0 \\
\hline 3 & Global & Cartesian & 3.1 & 11 & 1.2 & No & 3.1 & 11 & 1.2 \\
\hline 8 & Global & Cartesian & 2.7 & II & 4.1 & No & 2.7 & 11 & 4.1 \\
\hline 9 & Global & Cartesian & 3.4 & II & 12.3 & No & 3.4 & 11 & 12.3 \\
\hline 32 & Global & Cartesian & 3.1 & II & 0.9 & No & 3.1 & 11 & 0.9 \\
\hline 33 & Global & Cartesian & 3 & 11 & 2.4 & No & 3 & 11 & 2.4 \\
\hline 34 & Global & Cartesian & 2.4 & 11 & 5.6 & No & 2.4 & 11 & 5.6 \\
\hline 35 & Global & Cartesian & 2.2 & 11 & 6.9 & No & 2.2 & 11 & 6.9 \\
\hline 36 & Global & Cartesian & 2.3 & 11 & 8.4 & No & 2.3 & 11 & 8.4 \\
\hline 37 & Global & Cartesian & 2.6 & 11 & 10.1 & No & 2.6 & 11 & 10.1 \\
\hline 38 & Global & Cartesian & 3.3 & II & 11.9 & No & 3.3 & 11 & 11.9 \\
\hline 39 & Global & Cartesian & 3 & 14 & 0 & Yes & 3 & 14 & 0 \\
\hline 41 & Global & Cartesian & 3.1 & 14 & 1.2 & No & 3.1 & 14 & 1.2 \\
\hline 46 & Global & Cartesian & 2.7 & 14 & 4.1 & No & 2.7 & 14 & 4.1 \\
\hline 47 & Global & Cartesian & 3.4 & 14 & 12.3 & No & 3.4 & 14 & 12.3 \\
\hline 61 & Global & Cartesian & 3.1 & 14 & 0.9 & No & 3.1 & 14 & 0.9 \\
\hline 62 & Global & Cartesian & 3 & 14 & 2.4 & No & 3 & 14 & 2.4 \\
\hline 63 & Global & Cartesian & 2.4 & 14 & 5.6 & No & 2.4 & 14 & 5.6 \\
\hline
\end{tabular}


Table continued...

\begin{tabular}{|c|c|c|c|c|c|c|c|c|c|}
\hline Joint & Coord sys & Coord type & XorR & $\mathbf{Y}$ & $\mathbf{Z}$ & Special Jt & Global X & GlobalY & Global Z \\
\hline Text & Text & Text & $\mathrm{m}$ & $\mathrm{m}$ & $\mathrm{m}$ & Yes/No & $\mathrm{m}$ & $\mathrm{m}$ & $\mathrm{m}$ \\
\hline 64 & Global & Cartesian & 2.2 & 14 & 6.9 & No & 2.2 & 14 & 6.9 \\
\hline 65 & Global & Cartesian & 2.3 & 14 & 8.4 & No & 2.3 & 14 & 8.4 \\
\hline 66 & Global & Cartesian & 2.6 & 14 & 10.1 & No & 2.6 & 14 & 10.1 \\
\hline 67 & Global & Cartesian & 3.3 & 14 & 11.9 & No & 3.3 & 14 & 11.9 \\
\hline 68 & Global & Cartesian & 3 & 17 & 0 & Yes & 3 & 17 & 0 \\
\hline 70 & Global & Cartesian & 3.1 & 17 & 1.2 & No & 3.1 & 17 & 1.2 \\
\hline 75 & Global & Cartesian & 2.7 & 17 & 4.1 & No & 2.7 & 17 & 4.1 \\
\hline 76 & Global & Cartesian & 3.4 & 17 & 12.3 & No & 3.4 & 17 & 12.3 \\
\hline 90 & Global & Cartesian & 3.1 & 17 & 0.9 & No & 3.1 & 17 & 0.9 \\
\hline 91 & Global & Cartesian & 3 & 17 & 2.4 & No & 3 & 17 & 2.4 \\
\hline 92 & Global & Cartesian & 2.4 & 17 & 5.6 & No & 2.4 & 17 & 5.6 \\
\hline 93 & Global & Cartesian & 2.2 & 17 & 6.9 & No & 2.2 & 17 & 6.9 \\
\hline 94 & Global & Cartesian & 2.3 & 17 & 8.4 & No & 2.3 & 17 & 8.4 \\
\hline 95 & Global & Cartesian & 2.6 & 17 & 10.1 & No & 2.6 & 17 & 10.1 \\
\hline 96 & Global & Cartesian & 3.3 & 17 & 11.9 & No & 3.3 & 17 & 11.9 \\
\hline 97 & Global & Cartesian & 3 & 20 & 0 & Yes & 3 & 20 & 0 \\
\hline 99 & Global & Cartesian & 3.1 & 20 & 1.2 & No & 3.1 & 20 & 1.2 \\
\hline 104 & Global & Cartesian & 2.7 & 20 & 4.1 & No & 2.7 & 20 & 4.1 \\
\hline 105 & Global & Cartesian & 3.4 & 20 & 12.3 & No & 3.4 & 20 & 12.3 \\
\hline 119 & Global & Cartesian & 3.1 & 20 & 0.9 & No & 3.1 & 20 & 0.9 \\
\hline 120 & Global & Cartesian & 3 & 20 & 2.4 & No & 3 & 20 & 2.4 \\
\hline $12 \mid$ & Global & Cartesian & 2.4 & 20 & 5.6 & No & 2.4 & 20 & 5.6 \\
\hline 122 & Global & Cartesian & 2.2 & 20 & 6.9 & No & 2.2 & 20 & 6.9 \\
\hline 123 & Global & Cartesian & 2.3 & 20 & 8.4 & No & 2.3 & 20 & 8.4 \\
\hline 124 & Global & Cartesian & 2.6 & 20 & 10.1 & No & 2.6 & 20 & 10.1 \\
\hline 125 & Global & Cartesian & 3.3 & 20 & 11.9 & No & 3.3 & 20 & 11.9 \\
\hline 126 & Global & Cartesian & 2.2 & 11 & -2.9 & Yes & 2.2 & 11 & -2.9 \\
\hline 127 & Global & Cartesian & 2.2 & 14 & -2.9 & Yes & 2.2 & 14 & -2.9 \\
\hline 128 & Global & Cartesian & 2.2 & 17 & -2.9 & Yes & 2.2 & 17 & -2.9 \\
\hline 129 & Global & Cartesian & 2.2 & 20 & -2.9 & Yes & 2.2 & 20 & -2.9 \\
\hline 130 & Global & Cartesian & 2.8 & 20 & -1.5 & Yes & 2.8 & 20 & -1.5 \\
\hline$|3|$ & Global & Cartesian & 2.8 & 17 & -1.5 & Yes & 2.8 & 17 & -1.5 \\
\hline 132 & Global & Cartesian & 2.8 & 14 & -1.5 & Yes & 2.8 & 14 & -1.5 \\
\hline 133 & Global & Cartesian & 2.8 & 11 & -1.5 & Yes & 2.8 & 11 & -1.5 \\
\hline
\end{tabular}

The structural calculations for the typical panel are presented here being the dimension of which will govern the design for the rest of the curtain wall. Wind load is applied linear along the height that equals $2.3 \times 3=6.9 \mathrm{kN} / \mathrm{m}$. The additional dead load from the transoms and glass is applied on the Mullions and equals $0.78 \mathrm{KN} / \mathrm{m}$ (Figure 8). 

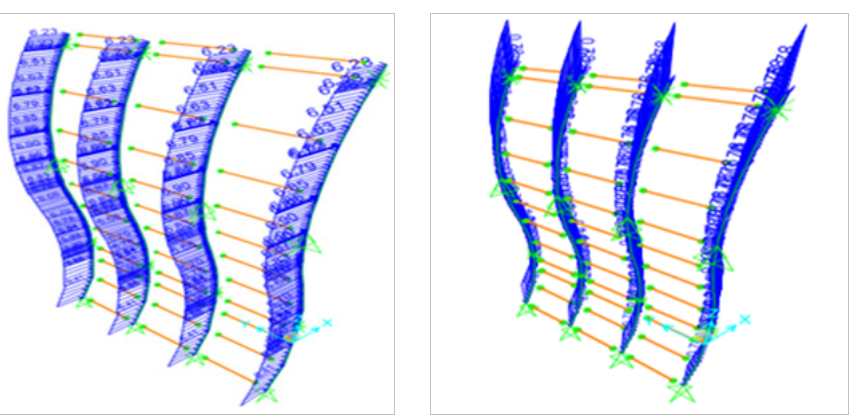

Figure 8 Curtain wall, (a) Wind loading (2.3kPa) and (b) Dead loading of glass and panels.

\section{Numerical results}

In this section, some results obtained from the numerical model are presented. Maximum Induced Stress in Mullions under ULS is $147.9 \mathrm{MPa}<$ The allowable bending stress $=160 \mathrm{MPa}$ (Figure 9). Maximum Deflection in Mullions is $17.88 \mathrm{~mm}$. Limiting value $=\mathrm{Span} / 175=6000 / 175=34.82 \mathrm{~mm}$ or $19 \mathrm{~mm}$ whichever is lesser (Figure 10).
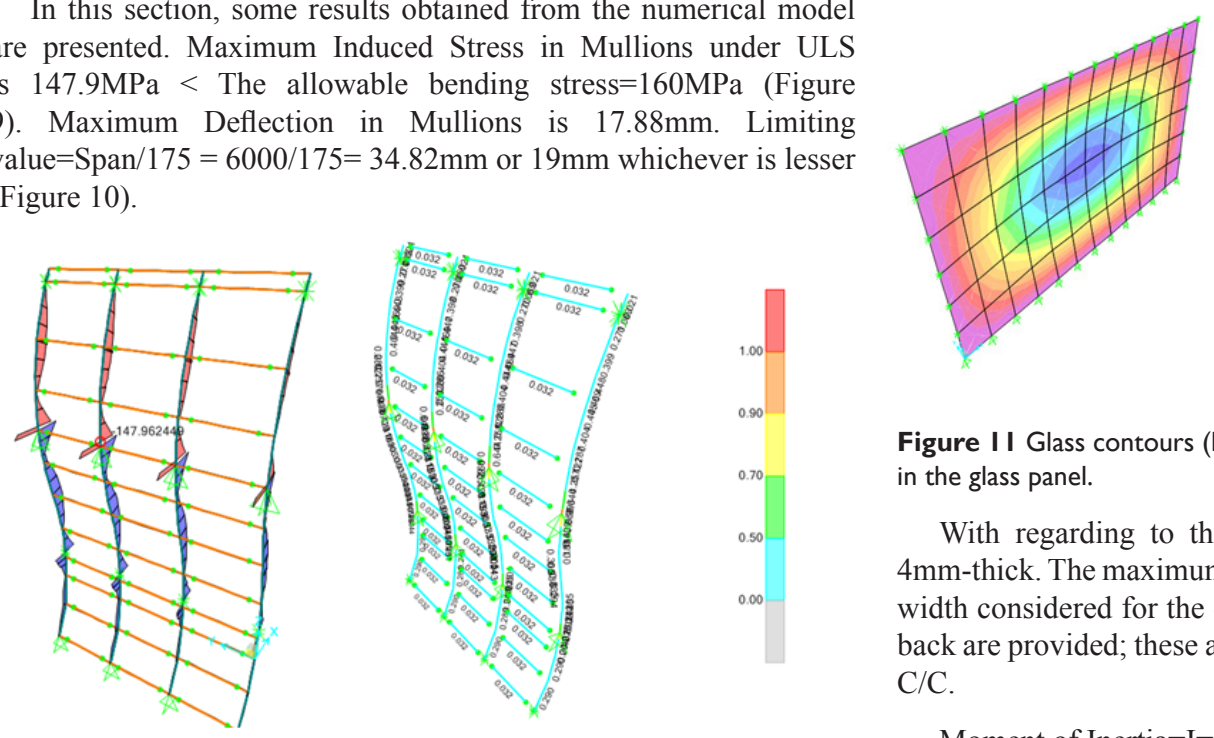

\section{Glass, composite panels and Transoms}

The numerical model for double glaze glass unit is realized in SAP 2000 through the use of shell elements. In general, the glass panel DGU is resting on mullions and transoms grid, and is checked for strength and deflection. Conservatively, it is assumed to be without the air gap and all the glass thicknesses are safe. The boundaries are considered pinned and the shell elements are meshed in such a way to obtain approximate stress results. The maximum glass size is $3000 \times 1980$ for which $8 \mathrm{~mm}$-thick glass external panel+(14 Air gap $)+6 \mathrm{~mm}$-thick glass internal panel. In SAP 2000, the outer and external panels are assumed to behave equally therefore these are considered as a single panel having a combine thickness of $14 \mathrm{~mm}$. Under the applied wind pressure, a maximum stress of $30.8 \mathrm{MPa}$ is under ultimate limit state (Figure 11). The deflection under serviceability limit state equals $15.4 \mathrm{~mm}<\mathrm{span} / 60=1980 / 60=33 \mathrm{~mm}$.
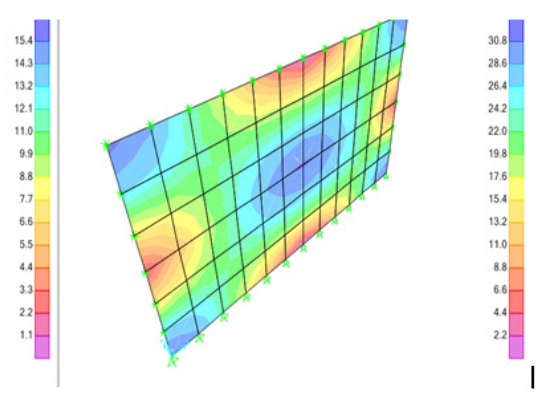

Figure I I Glass contours (left) obtained deflected shape and (right) stresses in the glass panel.

With regarding to the Aluminium composite panels, these are $4 \mathrm{~mm}$-thick. The maximum span for the panels is $3 \mathrm{~m}$ and the maximum width considered for the calculations purpose is $2 \mathrm{~m}$. Stiffeners at the back are provided; these are Aluminium tube $40 \times 40 \times 3$ at each $600 \mathrm{~mm}$ $\mathrm{C} / \mathrm{C}$.

Moment of Inertia $=\mathrm{I}=1682967 \mathrm{~mm}^{4}$

Perpendicular Distance to the N.A=Y=39 $\mathrm{mm}^{4}$

Wind $\mathrm{Load}=2.3 \mathrm{kN} / \mathrm{m}^{2}$

Wind Load $/ \mathrm{m}^{\prime}=\quad 6.9 \mathrm{kN} / \mathrm{m}^{\prime}$

Bending Moment $=\mathrm{BM}=6.9 \times 2 \times 2 \times 1.2 / 8=4.14 \mathrm{kN} . \mathrm{m}$ $\mathrm{OK}$

Flexural (Bending) Stress $=\mathrm{f}=\mathrm{M} . \mathrm{Y} / \mathrm{I}=95.94 \mathrm{MPa}<125 \mathrm{MPa}$

\section{Deflection $=12.20 \mathrm{~mm}<2000 / 90 \quad$ OK}

The composite panels are safe in carrying the applied loads due to the use of stiffeners at the back of the panels. Considering that transom carries dead load of glass, therefore, Linear load from glass on $3 \mathrm{~m}$ transom, carrying $3 \mathrm{~m}$ glass of $1.9 \mathrm{~m}$ height), being its self-weight equals $0.06 \mathrm{KN} / \mathrm{m}$ whereas, Self weight of glass $=0.665 \mathrm{KN} / \mathrm{m}$, hence total Load on transom for SLS $=0.06 \mathrm{KN} / \mathrm{m}+0.665 \mathrm{KN} / \mathrm{m}=0.72 \mathrm{KN} / \mathrm{m}$ (See Figure 11). Maximum Induced Deflection in Transom is $2.62 \mathrm{~mm}$ (Figure 12 \&13). Maximum Stress in Transom is $29.45 \mathrm{MPa}<\mathrm{The}$ allowable bending stress $=160 \mathrm{MPa}$ (Figure 14).

\section{Brackets checking}

The central Bracket is subjected to a total Tension of $51.9 \mathrm{KN}$ due (right). 
to wind suction and a shear of $24.55 \mathrm{KN}$ due to dead load of the curtain wall. These forces are obtained under Ultimate Limit States. The Bracket is realized in Robot structural analysis software ${ }^{3}$ see Figure 15. Since 4 \# M10 Stainless Steel bolts are used, therefore the forces are divided by 4 and applied at the center of the bolts in the numerical model (Figure 15). The loads are obtained from the Ultimate Limit State and are applied by default in dead load case. Maximum Induced Stress in the $12 \mathrm{~mm}$-thick Plate is $63.16 \mathrm{MPa}<275 \mathrm{MPa}$ (Figure 16), shows that the bracket is safe.

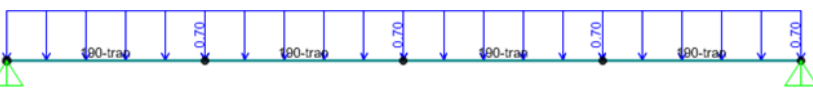

Figure 12 Numerical model of transoms with the dead load of glass.

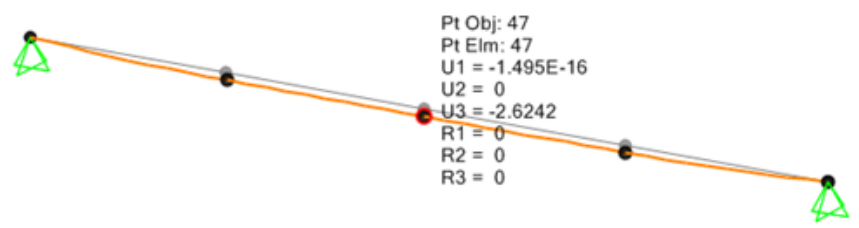

Figure 13 Induced deflection in transom $=2.62 \mathrm{~mm}<3.5 \mathrm{~mm}$.

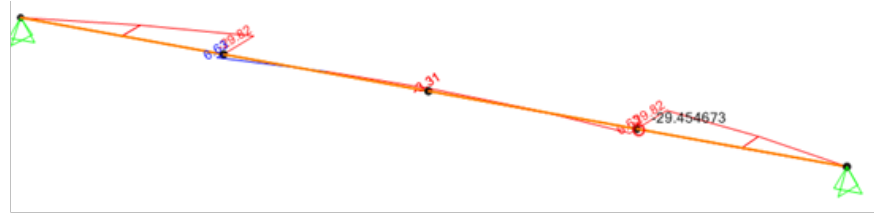

Figure 14 Stresses in the transoms $=29.45 \mathrm{MPa}<160 \mathrm{Mpa}$.
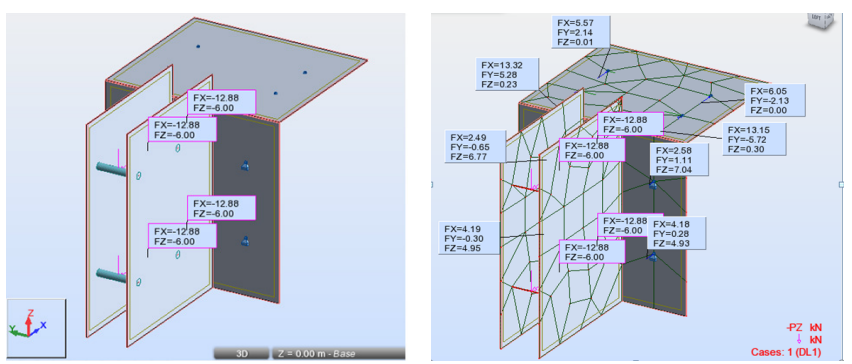

Figure I 5 Numerical model of bracket with loading (left) and meshing of the numerical model with reactions on anchors (right).

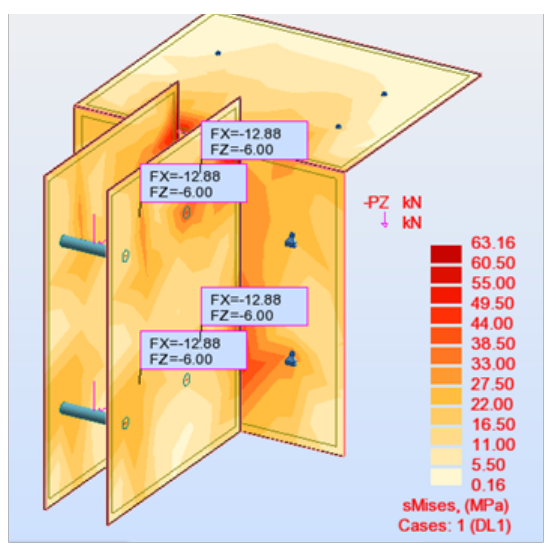

Figure 16 Stresses in the mild steel bracket.

\section{Conclusion}

The here presented paper dealt with the structural design of a complex curtain wall. Curving rectangular tubes to achieve double curvature mullions is generally not possible therefore mullions are built-up members fabricated from Aluminium sheets. The maximum glass panel is $3000 \mathrm{~mm} \times 1980 \mathrm{~mm}$ for which the double glazed glass unit $[8+(14$ Air gap $)+6]$ is adopted, that satisfy the strength and deflection. All anchors used are M12 of grade 8.8 with appropriate chemical in reinforced concrete having minimum embedment of $140 \mathrm{~mm} .12 \mathrm{~mm}$ thick mild steel welded brackets are used and found safe for transferring the applied loads. 6mm-fillet weld (throat thickness $4.2 \mathrm{~mm}$ ) of E35 Electrode is used for the mild steel brackets. The through stainless steel bolts holding the mullions in the brackets are M10 of property class 70 . For the composite panels which are only $4 \mathrm{~mm}$ thick Aluminium tubes $40 \times 40 \times 3 \mathrm{~mm}$ are used as stiffeners and are spaced at $600 \mathrm{~mm}$ center to center. The paper shows that the design of such curtain walls should take into account different practical issues such as the deflection and strength limitations of the glass under high wind loads, transoms strict deflection limitations to support the dead load of huge glass panels without breakage, mullion deflection limitations, and anchors to satisfy the minimum edge distances from the concrete face. The paper is believed to be beneficial for the technicians involved in the structural design of curtain walls.

\section{Acknowledgements}

None.

\section{Conflict of interest}

The author declares no conflict of interest.

\section{References}

1. Naqash MT, Formisano A, Matteis GD. Design and Performance Testing of a Skylight in Qatar. Switzerland: Trans Tech publications; 2016. p. 262-267.

2. CSI SAP V15. Integrated Finite Element Analysis and Design of Structures Basic Analysis Reference Manual. USA: Computers and Structures Inc; 2002.

3. Robot Structural Analysis. AUTODESK Robot Structural Analysis Professional 2014. 2014.

4. HILTI PROFIS 2.4.7. Hilti PROFIS Anchor software Hilti registered trademark of Hilti Corporation, 9494 Schaan Liechtenstein. 2011.

5. Leo Chan. Structural Use of Glass in Buildings. 2nd ed. The Institute of Structural Engineers; 1999. 3 p.

6. PrEN 13474-2. Glass in building-Design of glass panes-Part 2: Design for uniformly distributed loads. European Standard. 2000.

7. PrEN 13474-3. Glass in building-Determination of the strength of glass panes-Part 3: General method of calculation and determination of strength of glass by testing. European Standard. 2009. 35 p.

8. Nikolaos EM. Eurocode 1, Actions on structures-Part 1-1: General actions-Densities, self-weight, imposed loads for buildings. European Committee for Standardization. 2004.

9. EN-1990, Eurocode 0, Basis of structural design, in European Committee for Standardization, CEN, ed. 36 B-1050. Brussels; 2002.

10. Naqash MT, Formisano A, Matteis GD. Aluminium Framing Members in Facades. Switzerland: Trans Tech publications; 2016. p. 327-332.

11. Naqash MT. Structural Design Structural design of pergola with Airfoil louvers. The International Journal of Advanced Structures and Geotechnical Engineering. 2015;4(3):120-127.

12. Naqash MT. Structural Design Proposal for the Le Boulevard Skylight Doha Qatar. International Journal of Advanced Structures and Geotechnical Engineering. 2015;4(2):77-103. 